\title{
Grapefruit Juice Increases Felodipine Oral Availability in Humans by Decreasing Intestinal CYP3A Protein Expression
}

\author{
Kenneth S. Lown, ${ }^{\star}$ David G. Bailey, ${ }^{\ddagger}$ Robert J. Fontana, ${ }^{\star}$ Srinivas K. Janardan, ${ }^{\star}$ Constance H. Adair, ${ }^{\star}$ Laurie A. Fortlage, ${ }^{\star}$ \\ Morton B. Brown, $\$$ Wensheng Guo, $\$$ and Paul B. Watkins* \\ $*$ Department of Internal Medicine, University of Michigan; ${ }^{\ddagger}$ Department of Medicine, London Health Sciences Centre, Victoria Campus, \\ London, Ontario N6A 4G5, Canada; and ${ }^{\S}$ Department of Biostatistics, School of Public Health, University of Michigan, Ann Arbor, \\ Michigan 48109
}

\begin{abstract}
The increase in oral availability of felodipine and other commonly used medications when taken with grapefruit juice has been assumed to be due to inhibition of CYP3A4, a cytochrome P450 that is present in liver and intestine. To evaluate the effect of repeated grapefruit juice ingestion on CYP3A4 expression, 10 healthy men were given $8 \mathrm{oz}$ of grapefruit juice three times a day for $6 \mathrm{~d}$. Before and after receiving grapefruit juice, small bowel and colon mucosal biopsies were obtained endoscopically, oral felodipine kinetics were determined, and liver CYP3A4 activity was measured with the $\left[{ }^{14} \mathrm{C} \mathrm{N}\right.$-methyl] erythromycin breath test in each subject.

Grapefruit juice did not alter liver CYP3A4 activity, colon levels of CYP3A5, or small bowel concentrations of P-glycoprotein, villin, CYP1A1, and CYP2D6. In contrast, the concentration of CYP3A4 in small bowel epithelia (enterocytes) fell $62 \%(P=0.0006)$ with no corresponding change in CYP3A4 mRNA levels. In addition, enterocyte concentrations of CYP3A4 measured before grapefruit juice consumption correlated with the increase in $C_{\max }$ when felodipine was taken with either the 1st or the 16th glass of grapefruit juice relative to water $(r=0.67, P=0.043$, and $r=0.71, P=0.022$, respectively). We conclude that a mechanism for the effect of grapefruit juice on oral felodipine kinetics is its selective downregulation of CYP3A4 in the small intestine. (J. Clin. Invest. 1997. 99:2545-2553.) Key words: cytochrome P-450 • erythromycin • breath tests • multiple drug resistance $\cdot \mathrm{P}$-glycoprotein
\end{abstract}

\section{Introduction}

A single glass of grapefruit juice has been shown to significantly increase the oral availability of a variety of commonly used medications including felodipine (1), nifedipine (1), verapamil (2), terfenadine (3), ethinylestradiol (4), midazolam (5), saquinavir (6), and cyclosporin A $(7,8)$. The mechanism of this

Address correspondence to Paul B. Watkins, M.D., 1500 East Medical Center Drive, University Hospital, Room A7119-UH, Ann Arbor, Michigan, 48109-0108. Phone: 313-936-8080; FAX: 313-936-4024; E-mail: paul_watkins.gcrc@mailgw.surg.med.umich.edu

Received for publication 22 January 1997 and accepted in revised form 4 March 1997.

J. Clin. Invest.

(C) The American Society for Clinical Investigation, Inc.

0021-9738/97/05/2545/09 \$2.00

Volume 99, Number 10, May 1997, 2545-2553 effect is presumed to involve inhibition of metabolism rather than improved absorption, since many of the drugs affected appear to be well absorbed when taken in the absence of grapefruit juice (9-12).

Most of the drugs affected by grapefruit juice are known to be primarily metabolized by an enzyme termed CYP3A4 (1317). (The cytochromes $\mathrm{P} 450$ are a gene superfamily that has been divided into families that share greater than $40 \%$ amino acid sequence homology and subfamilies that share greater than $70 \%$ amino acid homology.) CYP3A4 is the most abundant cytochrome P450 present in both the liver (18) and in the epithelial cells (enterocytes) that line the lumen of the small bowel $(19,20)$. Grapefruit juice has been shown to contain substances that inhibit CYP3A4 (21-23) and it has therefore been assumed that the mechanism of its effect is CYP3A4 inhibition. Several lines of evidence suggest that the major site of CYP3A4 inhibition by grapefruit juice is the intestine rather than the liver. First, some drugs affected by grapefruit juice have been shown to undergo substantial metabolism by CYP3A4 within the small bowel $(10,12,24,25)$. In addition, grapefruit juice does not appear to influence the clearance of CYP3A4 substrates when they are administered intravenously $(5,8)$. Finally, the primary effect of grapefruit juice on orally administered medications is to increase peak serum concentration $\left(C_{\max }\right)$ with little change in the subsequent rate of elimination as measured by half-life (26).

Repeated administration of potent inhibitors of CYP3A enzymes often causes upregulation of CYP3A mRNA and protein (i.e., inhibitors are also often inducers). For example, imidazole antimycotic drugs inhibit CYP3A catalytic activity acutely, but result in an upregulation of CYP3A mRNA and protein concentrations in rat liver and intestine with continued administration $(27,28)$. Some macrolide antibiotics have also been shown to inhibit CYP3A enzymes with a resulting increase in CYP3A mRNA and protein in rat and human liver with recurrent administration $(29,30)$. Previous studies have not evaluated whether the magnitude of the grapefruit juice effect on drugs remains constant during recurrent grapefruit juice treatment. If a component of grapefruit juice inhibits intestinal CYP3A4, we speculated that continued grapefruit juice intake might result in an upregulation of this enzyme. We reasoned that if this occurred, the effect of grapefruit juice on the oral kinetics of CYP3A4 substrates would then diminish over time.

To directly test this hypothesis, we evaluated the effect of recurrent grapefruit juice ingestion on intestinal and hepatic levels of CYP3A4 and on felodipine oral pharmacokinetics in healthy volunteers. Felodipine was chosen because it is completely absorbed after oral administration with water (9) and its interaction with grapefruit juice has been well characterized $(1,26)$. 


\section{Methods}

\section{Subjects}

The study was performed in 15 healthy male volunteers; 10 were enrolled in a 12-d inpatient study and 5 were enrolled in an outpatient study. To be included in the study, subjects had to be between 18 and $65 \mathrm{yr}$ of age, be taking no medications, and have no significant medical problems. This study was approved by the University of Michigan Institutional Review Board. Written informed consent was obtained from all subjects.

\section{Experimental design}

In the inpatient experimental protocol, 10 subjects were admitted to the University of Michigan General Clinical Research Center (GCRC) for the duration of their involvement in the study. Detailed diet dairies were prospectively filled out by each subject for the $3 \mathrm{~d}$ before admission. No subject consumed any grapefruit or grapefruit juice in the $3 \mathrm{~d}$ before the study. The GCRC dietary staff prepared meals containing sufficient calories to maintain each subject's weight based on his or her total body weight. Except for total calories, all subjects received identical meals. On days 1-12 of the study, subjects were placed on a diet devoid of fruits and vegetables. Starting on the sixth day, an $8 \mathrm{oz}$ glass of regular strength grapefruit juice (from a single lot of "Kroeger" brand, frozen concentrate) was added to breakfast, lunch, and dinner.

The pharmacokinetics of oral felodipine were determined after the administration of a 10-mg tablet of felodipine (Plendil ${ }^{\circledR}$; Astra Merck Inc., Wayne, PA) at $\sim 0900$ hours on three occasions during the study. The first tablet of felodipine was given on the fourth day of the study with an $8 \mathrm{oz}$ glass of water. The second tablet was taken on day 6 with the first $8 \mathrm{oz}$ glass of grapefruit juice received by the subject. The final tablet of felodipine was taken on day 11 with the 16th glass of grapefruit juice.

Liver activity of CYP3A4 was determined using the $\left[{ }^{14} \mathrm{C}-\mathrm{N}\right.$ methyl] erythromycin breath test (ERMBT) ${ }^{1}$ before the subjects received their first dose of felodipine (morning of day 4) and again just before they received their 16th glass of grapefruit juice (morning of day 11).

Proximal small bowel mucosal biopsies were obtained by upper intestinal endoscopy from each subject at entry to the study (day 1), the day before the addition of grapefruit juice to the diet (day 5), and after the last glass of grapefruit juice (day 12). Colonic mucosal biopsies were also obtained from each subject by flexible sigmoidoscopy on days 5 and 12 . The study was completed and the subjects were discharged from the GCRC after recovering from the sedation given for the endoscopy on day 12 .

In the outpatient study, five healthy male volunteers were given the ERMBT before and again 2 and $6 \mathrm{~h}$ after ingesting $8 \mathrm{oz}$ of regular strength grapefruit juice.

\section{Intestinal measurements}

Endoscopy. Each subject underwent upper intestinal endoscopy and flexible sigmoidoscopy after fasting for $4 \mathrm{~h}$ after breakfast. Subjects were sedated with intravenous midazolam (Roche Pharmaceuticals, Nutley, NJ) and meperidine (Sanofi Winthrop, New York) and a fiber-optic endoscope was used to obtain 10 mucosal biopsies from the second portion of the duodenum and 10 mucosal biopsies from the sigmoid colon. Five of the biopsies from each set were immediately placed in ice cold solution D (0.05 M Tris hydrochloride, $20 \%$ glycerol, and $2 \mathrm{mM}$ EDTA; reference 31), homogenized in a glass dounce, and snap frozen in liquid nitrogen. The other five biopsies from each set were immediately placed in $500 \mu \mathrm{l}$ denaturing solution (4 M guanidine isothiocyanate, $0.5 \% \mathrm{~N}$-lauroylsarcosine, $25 \mathrm{mM}$ so-

1. Abbreviations used in this paper: AUC, area under the curve; ERMBT, erythromycin breath test. dium citrate, and 0.7\% 2-mercaptoethanol, $\mathrm{pH} 7.0$ ), homogenized in a glass dounce and snap frozen in liquid nitrogen.

Immunoblotting. Immunoblots were performed as previously described (32) with the following modifications. Whole biopsy homogenate $(25 \mu \mathrm{g}$ of small bowel or $100 \mu \mathrm{g}$ of colon), rather than S9 fraction, were immunoblotted without heating before electrophoresis. We have found that, compared with whole homogenate, $>80 \%$ of CYP3A4 immunoreactive protein is lost during preparation of the S9 fraction used in our earlier study (reference 32; data not shown). In addition, using whole homogenate allowed us to simultaneously probe a single blot for villin (a cytosolic protein), cytochrome P450 enzymes (microsomal proteins), and P-glycoprotein (a plasma membrane-bound protein).

Small intestinal CYP3A4 protein was detected using either 13-710, a mouse monoclonal antibody (32), or anti-Hlp, a rabbit polyclonal antibody (reference 33; a gift from Dr. Steven A. Wrighton, Eli Lilly Corporation, Indianapolis, IN). CYP3A5 in the small intestine was detected using an immunoadsorbed polyclonal antibody specific for CYP3A5 (reference 33; a gift from Dr. Steven A. Wrighton). CYP3A5 in colon was detected using the 13-7-10 antibody. Intestinal CYP2D6 protein was detected using a polyclonal rabbit antibody (34) obtained as a gift from Dr. Alastair Cribb (Merck Research Laboratories, West Point, PA). CYP1A1 was detected using a polyclonal goat antibody (GENTEST Corp., Woburn, MA) developed against rat CYP1A1 and CYP1A2 that cross-reacts with the human forms of these proteins. P-glycoprotein was detected using the antibody MDRAb1 (Oncogene Science, Inc., Manhasset, NY), a rabbit polyclonal antibody to human P-glycoprotein. Villin was detected with a mouse monoclonal antibody raised against chick villin that cross-reacts with human villin (Chemicon International Inc., Temecula, CA). The secondary antibodies used included horseradish peroxidase-conjugated rabbit anti-mouse IgG, goat anti-rabbit IgG/A/M (Zymed Laboratories Inc., South San Francisco, CA), and mouse anti-goat IgG/A/M (Pierce, Rockford, IL).

After all antibody incubations were completed, the blots were developed with a chemiluminescence kit (Amersham Corp., Arlington Heights, IL) and exposed to ECL Hyperfilm (Amersham Corp.). Immunoblot protein concentrations were determined by computeraided densitometry with a Macintosh computer using the public domain National Institutes of Health (NIH) Image program (developed at the NIH and available on the Internet at http://rsb.info.nih.gov/nihimage/). Optical densities were converted to quantitative numbers by comparison with slot blots of serial dilutions of purified CYP3A4 protein that had been processed simultaneously with the immunoblots and exposed on the same films and for the same time duration as the protein being quantitated. This allowed for correction of the nonlinearity of electrochemiluminescence light output and the ECL Hyperfilm.

To obtain accurate measures of P-glycoprotein and CYP3A4, immunoblots were repeated a minimum of six times. Final values were calculated from the arithmetic mean of all of the runs with any outlying points (i.e., $>2 \mathrm{SD}$ from the mean for that sample) omitted.

Correction for interbiopsy variation of enterocyte content. CYP3A4 and P-glycoprotein are expressed exclusively in mature enterocytes in the intestine $(19,20,35)$. Enterocytes represent only a small fraction of the cells obtained in an intestinal biopsy. We have previously found that there is significant interbiopsy variation in the content of mature enterocytes even among biopsies obtained from a single individual (32). Differences in the percent enterocyte content in individual intestinal biopsies will alter the amount of immunoreactive protein observed on a blot (32). For example, a deep mucosal biopsy would contain a relatively low proportion of enterocytes, whereas a more superficial biopsy would have a relatively high proportion of enterocytes per milligram of protein.

Villin, an enterocyte-specific, constitutively expressed protein, is able to control for the variation in biopsy content of mature enterocytes (32). Therefore, biopsy levels of CYP3A4 and P-glycoprotein were expressed as a ratio with the villin level of the same sample (i.e., 
CYP3A4/villin and P-glycoprotein/villin). These villin-corrected values provide a relative measure of enterocyte concentration and for the sake of simplicity have been termed "enterocyte concentration" in the text.

RNA analysis. Biopsy samples were quickly thawed and the RNA extracted by the method of Chomczynski and Sacchi (36). $30 \mu \mathrm{g}$ total RNA from each patient were subjected to electrophoresis on a formaldehyde agarose gel and transferred to nylon membranes. The blots were hybridized with previously described radiolabeled probes for CYP3A4 and villin (32). The relative hybridization intensities of the CYP3A4 and villin cDNAs were quantitated by computer-aided densitometry and expressed as arbitrary optical density units.

\section{Erythromycin breath test}

The in vivo catalytic activity of hepatic CYP3A4 can be conveniently and noninvasively estimated as the rate at which ${ }^{14} \mathrm{CO}_{2}$ is exhaled after an intravenous test dose of $\left[{ }^{14} \mathrm{C}-N\right.$-methyl $]$ erythromycin. The ERMBT result correlates well with the liver content of CYP3A4 in subjects undergoing liver transplantation and does not correlate with the liver content of five other major liver P450s (37).

The ERMBT was administered as previously described (38) with the modification that subjects were given a $0.074 \mathrm{mmol}(0.0543 \mathrm{mg}, 3$ $\mu \mathrm{Ci})$ dose of $\left[{ }^{14} \mathrm{C}-\mathrm{N}\right.$-methyl] erythromycin. Breath test results were expressed as the percentage of administered ${ }^{14} \mathrm{C}$ that was exhaled during the first hour after the injection of erythromycin (38), estimated from the rate of radiolabel exhalation at $20 \mathrm{~min}$ as previously described (39).

\section{Felodipine assay}

The plasma concentration of felodipine was measured at $0,0.5,1,1.5$, $2,2.5,3,4,5,6,8,12$, and $24 \mathrm{~h}$ after each administration of felodipine. The plasma concentrations of felodipine were quantitated using a previously published method (40) with modifications. Briefly, plasma $(200 \mu \mathrm{l})$ was extracted with toluene $(200 \mu \mathrm{l})$ containing the internal standard (H165/04; AB Haessle, Gothenburg, Sweden) by oscillating the mixture overnight. After centrifugation, a sample of the toluene extract $(1 \mu \mathrm{l})$ was introduced by splitless injection into a dual taper deactivated glass insert (Hewlett Packard Canada Ltd., Toronto, Ontario, Canada). Chromatography was performed on a gas chromatograph (5890 Series II; Hewlett Packard Canada Ltd.) equipped with a ${ }^{63} \mathrm{Ni}$ electron capture detector and a capillary column $25 \mathrm{~m} \times 0.32 \mathrm{~mm}$ i.d. fused silica coated with stationary phase of methyl silicone 0.52 $\mu \mathrm{m}$ (HP-1; Hewlett Packard Canada Ltd.). After purge at $1 \mathrm{~min}$, the initial oven temperature of $90^{\circ} \mathrm{C}$ was increased at $30^{\circ} \mathrm{C} / \mathrm{min}$ to $180^{\circ} \mathrm{C}$, and then $5^{\circ} \mathrm{C} / \mathrm{min}$ to $260^{\circ} \mathrm{C}$ for $3 \mathrm{~min}$, followed by $30^{\circ} \mathrm{C} / \mathrm{min}$ to a final temperature of $280^{\circ} \mathrm{C}$ for $5 \mathrm{~min}$. The injector port and detector temperatures were maintained at 260 and $300^{\circ} \mathrm{C}$, respectively. The carrier gas was ultrapure helium (column inlet pressure of $100 \mathrm{kPa}$ ) and the make-up gas was ultrapure nitrogen $(60 \mathrm{ml} / \mathrm{min})$. The retention times of felodipine and internal standard were 20.1 and $21.7 \mathrm{~min}$, respectively. The interday coefficient of variation for plasma felodipine con- centration at $13 \mathrm{nmol} /$ liter was $3.2 \%(n=8)$. The limit of detection was $<1.0 \mathrm{nmol} /$ liter.

\section{Pharmacokinetic analysis}

Plasma felodipine concentrations were analyzed by a noncompartmental method. The peak drug concentration $\left(C_{\max }\right)$ was obtained directly from the experimental data. The area under the plasma drug concentration-time curve (AUC) was calculated from 0 to $12 \mathrm{~h}$ by the linear trapezoidal method. The AUC was determined over $12 \mathrm{~h}$ because 7 of the 10 subjects had at least one of their plasma levels below the level of detection at the $24-\mathrm{h}$ time point. We have previously shown that the ERMBT result should be compared with the pharmacokinetic parameters of a drug corrected for body weight (32). Hence, $C_{\max }$ and AUC values were expressed relative to the dose of felodipine in milligrams per kilograms before correlations with the ERMBT were determined.

\section{Statistical analysis}

Statistical analysis of the data was performed using StatView 4.5 (Abacus Concepts Inc., Berkeley, CA) and SAS (SAS Institute, Inc., Cary, NC). All values are expressed as the mean \pm SD with the exception of Fig. 5, which displays data with standard error bars. Correlations between variables were determined using the Spearman rank correlation, a nonparametric measure of statistical significance that does not depend on an assumption of normality. Comparison of means was determined using a paired two tailed $t$ test that does assume a normal distribution of the data. The small number of data points for each variable were often skewed and the variances of the variable depended on its mean level. The values of felodipine $C_{\max }$ and AUC, intestinal CYP3A4, ERMBT result, and intestinal P-glycoprotein were therefore $\log$ transformed to normalize their distributions before $t$ test analysis. Results were considered significant for $P<0.05$.

\section{Results}

10 healthy adult volunteers participated in the 12-d inpatient protocol evaluating the effect of grapefruit juice ingestion. The mean baseline enterocyte concentration of CYP3A4 protein (CYP3A4/villin) and of another enterocyte-specific protein, P-glycoprotein (P-glycoprotein/villin), are shown in Table I. P-glycoprotein, the gene product of mdr1 (41), is a versatile transporter that is expressed in many tissues, including the intestine, where it is almost exclusively expressed within the apical (lumenal) plasma membranes of enterocytes $(35,42)$. In the intestine, $\mathrm{P}$-glycoprotein functions to pump a wide variety of xenobiotics including many CYP3A4 substrates such as cyclosporin A $(43,44)$ from the cytoplasm to the exterior of the cell (i.e., from the enterocyte back into the intestinal lumen).

Table I. Intestinal and Hepatic CYP3A and Intestinal P-Glycoprotein

\begin{tabular}{|c|c|c|c|c|c|}
\hline Study day & $\begin{array}{c}\text { Enterocyte* } \\
\text { CYP3A4 protein concentration }\end{array}$ & $\begin{array}{c}\text { Enterocyte* } \\
\text { CYP3A4 mRNA concentration }\end{array}$ & $\begin{array}{c}\text { Enterocyte* }^{*} \\
\text { CYP3A5 protein concentration }\end{array}$ & $\begin{array}{c}\text { ERMBT } \\
\text { (percent }{ }^{14} \mathrm{C} / \mathrm{h} \text { ) }\end{array}$ & $\begin{array}{c}\text { Enterocyte* } \\
\text { P-glycoprotein concentration }\end{array}$ \\
\hline 1 & $88.1 \pm 50.1$ & & & & $76.2 \pm 17.9$ \\
\hline 4 & & & & $2.50 \pm 0.54$ & \\
\hline 5 & $93.8 \pm 40.1$ & $36.1 \pm 33.0$ & $96.4 \pm 43.8$ & & $95.1 \pm 27.7^{\ddagger}$ \\
\hline 11 & & & & $2.52 \pm 0.67$ & \\
\hline 12 & $35.2 \pm 10.9^{\S}$ & $43.2 \pm 48.1$ & $41.2 \pm 32.1^{\|}$ & & $103.6 \pm 36.6$ \\
\hline
\end{tabular}

*Enterocyte CYP3A4, CYP3A5, and P-glycoprotein concentration are expressed as the ratio of the computer-determined densitometric value of the protein or mRNA of interest relative to villin (see Methods for details). ${ }^{\ddagger} P=0.05$ compared with intestinal P-glycoprotein on day 1 of the study. ${ }^{\S} P=$ 0.0006 and 0.0001 compared with intestinal CYP3A4 on days 1 and 5 , respectively. ${ }^{\|}=0.002$ compared with intestinal CYP3A5 on day 5 . 


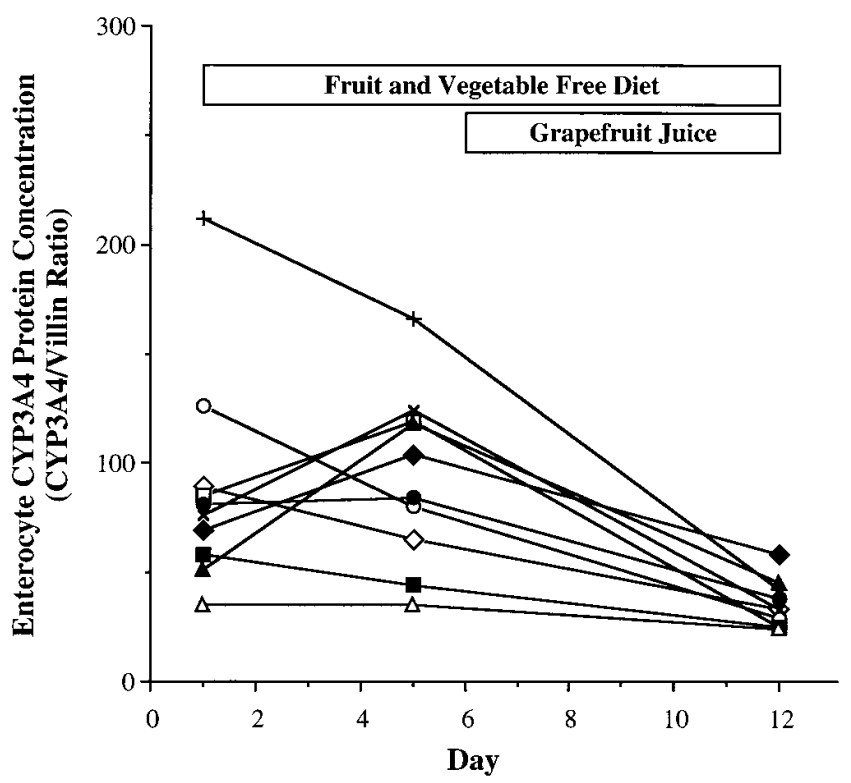

Figure 1. The effect of grapefruit juice on enterocyte concentration of CYP3A4. CYP3A4/villin protein ratios were determined from small bowel mucosal biopsies (as described in Methods) at entry to the study (day 1), after $4 \mathrm{~d}$ on a fruit- and vegetable-free diet (day 5), and after $6 \mathrm{~d}$ of ingesting $8 \mathrm{oz}$ of grapefruit juice three times a day (day 12). Subject number $1, \bigcirc ; 2, \boldsymbol{\bullet} ; 3, \square ; 4, \mathbf{\square} ; 5, \triangle ; 6, \mathbf{\Delta} ; 7,+; 8, \times$; $9, \diamond ;$ and 10

The other member of the MDR gene family in humans, mdr2, is not significantly expressed in human intestine (45), so protein detected by the MDR-Ab1 antibody on immunoblots of intestinal protein will reflect the mdr1 gene product.
The enterocyte concentrations of CYP3A4 and P-glycoprotein were highly variable and ranged from 34.8 to 212.2 and 59.2 to 119.0, respectively (see Table I and Fig. 2). There was no significant intrasubject correlation between the enterocyte concentration of CYP3A4 and P-glycoprotein at any of the three time points.

As shown in Table I and Fig. 1, $5 \mathrm{~d}$ on the fruit- and vegetable-free diet did not consistently alter the enterocyte concentration of CYP3A4, as the mean CYP3A4/villin ratio on day 5 was unchanged from the ratio at entry to the study (93.8 \pm 40.1 and $88.1 \pm 50.1 \mathrm{SD}$, respectively, $P=0.55)$. The mean enterocyte concentration of P-glycoprotein was higher on day 5 than at entry into the study $(95.1 \pm 27.7$ vs. $76.2 \pm$ 17.9 , respectively, $P=0.05$; see Table I). The relative ranges (ratios of highest to lowest values) of CYP3A4 and P-glycoprotein were unchanged after $5 \mathrm{~d}$ on the fruit- and vegetablefree diet.

The final small bowel biopsies were obtained after the subjects had ingested grapefruit juice for $6 \mathrm{~d}$ (day 12). Contrary to our hypothesis that recurrent grapefruit juice treatment would result in a compensatory increase in intestinal CYP3A4, the addition of grapefruit juice to the diet resulted in a drop in the enterocyte CYP3A4 concentration in every subject (Figs. 1 and 2 and Table I). The mean enterocyte CYP3A4 protein concentration decreased $62 \%$ from day 5 to day 12 (from $93.8 \pm 40.1$ to $35.2 \pm 10.9, P=0.0001$, Table I). In contrast, the mean enterocyte P-glycoprotein concentration did not significantly change from day 5 to day 12 (from $95.0 \pm 27.7$ to 103.6 $\pm 36.6, P=0.52$; Table I).

One possible explanation for the decrease in CYP3A4 immunoreactivity observed on the immunoblots (Fig. 2) is that the epitope recognized by the monoclonal antibody, 13-7-10, was altered or blocked by an interaction between the enzyme

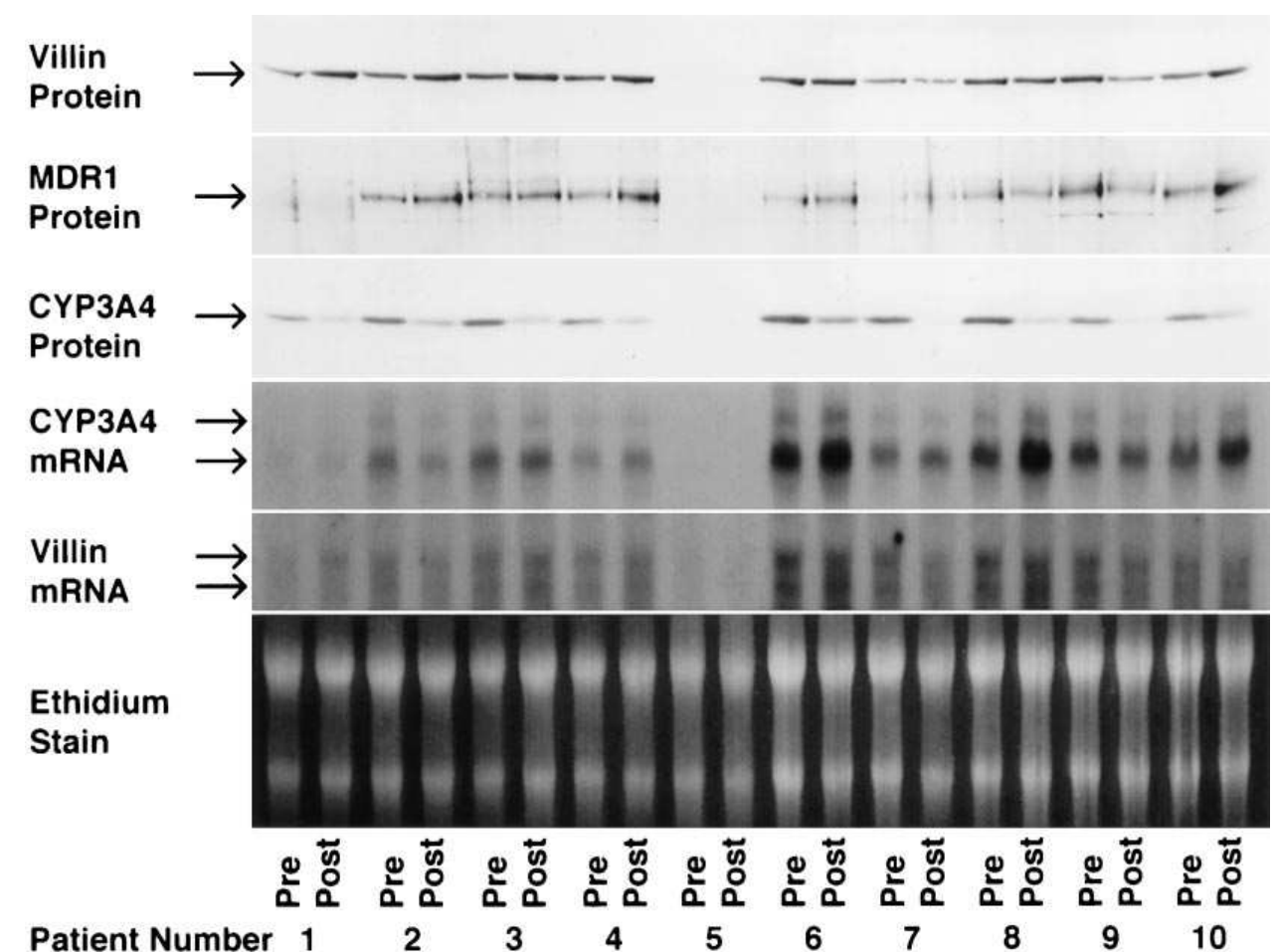

Figure 2. Representative immunoblot of intestinal CYP3A4, P-glycoprotein, and villin proteins and a Northern blot of CYP3A4 and villin mRNAs. The small bowel biopsies assayed were obtained before (Pre) and after (Post) $6 \mathrm{~d}$ of thrice daily grapefruit juice ingestion. The top three lanes are a single immunoblot of whole biopsy homogenate ( 25 $\mu \mathrm{g})$ simultaneously developed with antibodies to villin, P-glycoprotein, and CYP3A4 protein. The blot was exposed to ECL Hyperfilm for different durations to obtain appropriate exposure for CYP3A4 (1 s), villin (10 s), and P-glycoprotein (5 $\min$ ). The signals obtained from the biopsies of patient 5 were markedly less intense than those obtained from biopsies from other patients. Prolonged exposure of the blot revealed immunoreactive bands for each of the proteins assayed, and a fall in CYP3A4 protein content was evident (not shown). The lower three lanes show a Northern blot of intestinal RNA $(30 \mu \mathrm{g})$. The ethidium stain of the RNA after electrophoresis in a formaldehyde-containing agarose gel is shown in the lowest section of the figure. The RNA was transferred to nitrocellulose and sequentially hybridized with CYP3A4 and villin cDNA as described in Methods. 


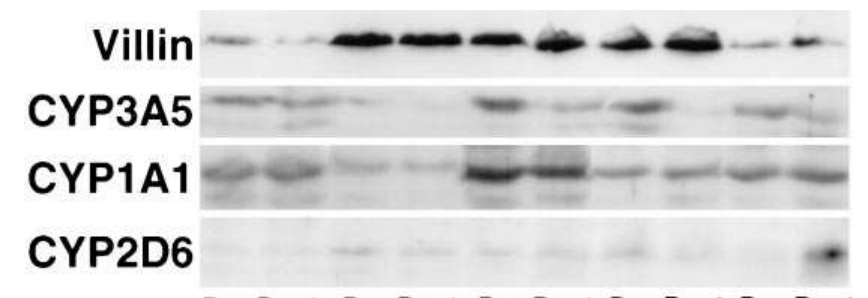

Pre Post Pre Post Pre Post Pre Post Pre Post

Figure 3. Representative immunoblots of small bowel villin,

CYP3A5, CYP1A1, and CYP2D6 proteins. $50 \mu \mathrm{g}$ of homogenate prepared from biopsies obtained before (Pre) and after (Post) $6 \mathrm{~d}$ of thrice daily grapefruit juice ingestion were analyzed by immunoblotting. The poorer quality of the blots relative to that shown in Fig. 2 relates to the larger amount of protein loaded and the longer exposure times necessary for visualization of the proteins.

and a component in grapefruit juice. However, essentially identical results were obtained when immunoblots of intestinal biopsy protein were probed with a polyclonal CYP3A4 antibody, anti-Hlp (not shown).

We also examined the effect of grapefruit juice on CYP3A4 mRNA expression. The mean enterocyte CYP3A4 mRNA concentration (CYP3A4 mRNA/villin mRNA) was $36.1 \pm 33.0$ before grapefruit juice ingestion (day 5) in the nine subjects with quantifiable mRNA. The mean enterocyte CYP3A4 mRNA concentration was unchanged after $6 \mathrm{~d}$ of grapefruit juice intake (43.2 $\pm 48.1, P=0.66$, Fig. 2 and Table I). There was no significant correlation between enterocyte CYP3A4 mRNA and CYP3A4 protein concentration on ei-

\section{Villin ..- - ...... CYP3A5 \\ Pre Post Pre Post Pre Post Pre Post}

Figure 4. Representative immunoblot of colonic mucosal villin and CYP3A5 protein. $100 \mu \mathrm{g}$ of whole homogenate from colonic mucosal biopsies obtained before (Pre) and after (Post) $6 \mathrm{~d}$ of thrice daily grapefruit juice ingestion were subjected to immunoblot analysis as described in Methods.

ther day 5 or day 12 , consistent with the findings of our earlier study (32).

Repeated grapefruit juice treatment also resulted in a significant fall in the small bowel biopsy content of CYP3A5 protein (Fig. 3 and Table I). CYP3A5 is another member of the CYP3A subfamily of cytochrome P450 enzymes with catalytic properties similar to CYP3A4, but which appears to be present in lower abundance in the small bowel epithelia (32). The mean intestinal CYP3A5 concentration (expressed as CYP3A5/villin) fell $57 \%$ from day 5 to day 12 in the nine subjects with measurable CYP3A5 protein (96.4 \pm 43.8 to $41.2 \pm 32.1, P=0.002$ ).

To determine whether the drop in both CYP3A4 and CYP3A5 protein reflected a global reduction in intestinal cytochrome P450 enzymes, we also measured the enterocyte content of CYP2D6 and CYP1A1. CYP2D6 and CYP1A1 are cy-

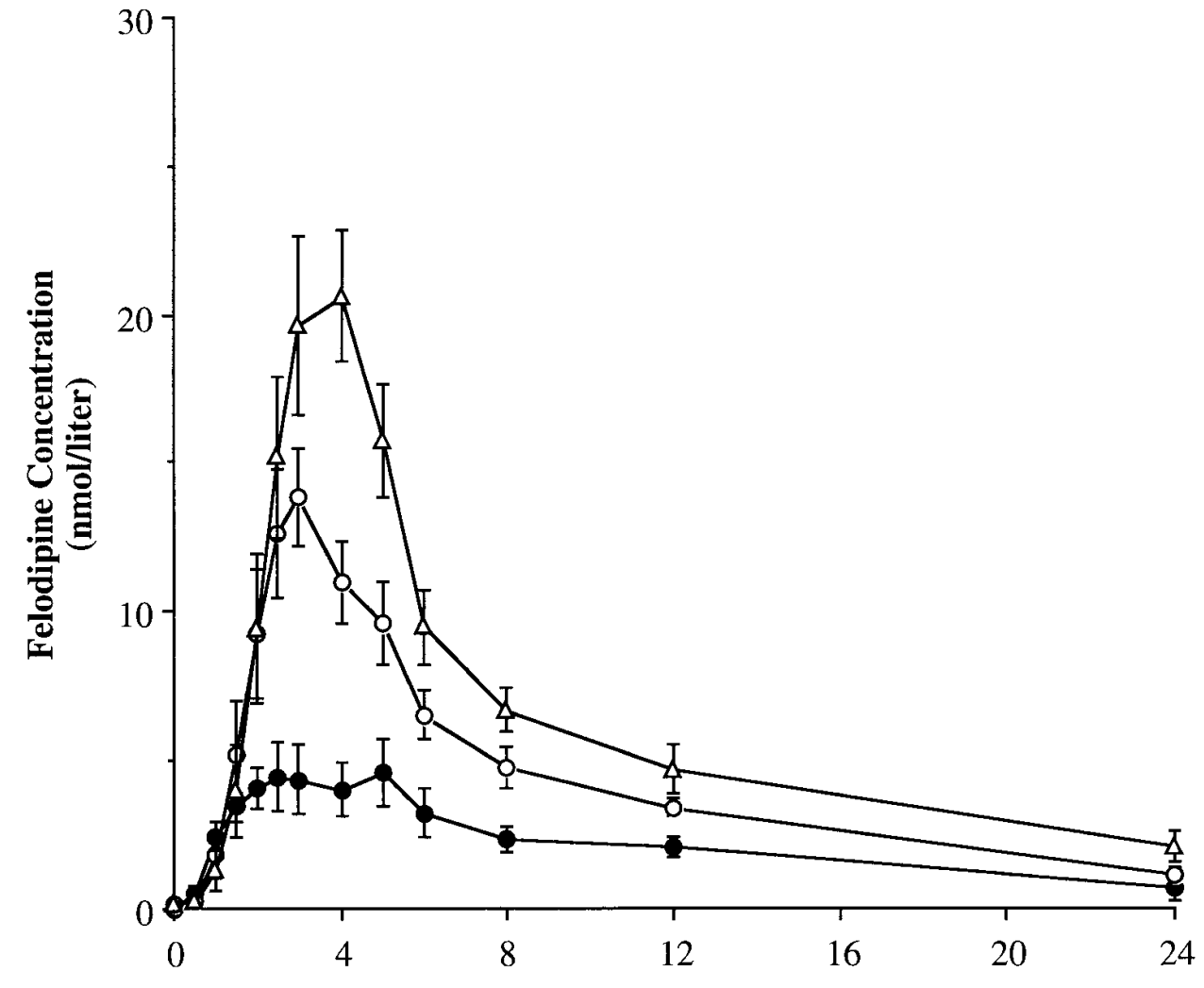

Time (hours)
Figure 5. Effect of grapefruit juice on mean felodipine plasma concentrations. Felodipine plasma concentrations were measured after the oral administration of $10 \mathrm{mg}$ felodipine with either water $(\bullet)$, after the first 8-oz glass of grapefruit juice $(\bigcirc)$, or after $5 \mathrm{~d}$ of thrice daily administration of grapefruit juice $(\triangle)$. Bars indicate standard errors. 
Table II. Felodipine Oral Pharmacokinetic Parameters

\begin{tabular}{|c|c|c|c|c|}
\hline Treatment & $\mathrm{C}_{\max }$ & $\mathrm{C}_{\max }$ coefficient of variation & AUC & AUC coefficient of variation \\
\hline & nmol/liter & & nmol-h/liter & \\
\hline Water & $5.5 \pm 3.4$ & $61 \%$ & $35.3 \pm 21.6$ & $61 \%$ \\
\hline Acute grapefruit juice & $17.9 \pm 3.3 *$ & $18 \%$ & $76.4 \pm 15.6^{*}$ & $20 \%$ \\
\hline Chronic grapefruit juice & $23.9 \pm 8.53^{\S}$ & $36 \%$ & $109.8 \pm 35.3^{\|}$ & $32 \%$ \\
\hline
\end{tabular}

All values \pm SD. $\mathrm{C}_{\max }$, peak blood concentration. ${ }^{*} P=0.0001$ compared with felodipine given with water. ${ }^{*} P<0.05$ compared with felodipine given with water. ${ }^{\S} P=0.044$ compared with felodipine given with a single glass of grapefruit juice. $\| P=0.0023$ compared with felodipine given with a single glass of grapefruit juice.

tochrome P450s that are also expressed in the intestine, but that are unrelated to the CYP3A subfamily. As can be seen in representative immunoblots in Fig. 3, there was no consistent change in the level of enterocyte CYP2D6 or CYP1A1 protein with recurrent grapefruit juice ingestion.

We also examined whether grapefruit juice ingestion affected the expression of CYP3A enzymes present in colon and liver. The 13-7-10 antibody we used reacts with all CYP3A proteins. However, since CYP3A5 is the major CYP3A protein present in colon (46), immunoreactive protein detected with 13-7-10 in colon should reflect primarily CYP3A5 protein. There was no significant change in the concentration of CYP3A5 in the sigmoid colon biopsies obtained from the subjects on days 5 and 12 (Fig. 4). There was also no significant change in the level of liver CYP3A4 activity as measured by the ERMBT after grapefruit juice treatment. The mean ERMBT result was $2.50 \pm 0.54 \%{ }^{14} \mathrm{C} / \mathrm{h}$ before grapefruit juice (day 4) and $2.52 \pm 0.67 \%{ }^{14} \mathrm{C} / \mathrm{h}$ after repeated grapefruit juice (day $11, P=0.88$, see Table I). In addition, the ERMBT result was unchanged in the five individuals that underwent the ERMBT before (mean $2.82 \pm 0.22 \%{ }^{14} \mathrm{C} / \mathrm{h}$ ), $2 \mathrm{~h}$ (mean $2.55 \pm 0.22 \%{ }^{14} \mathrm{C} / \mathrm{h}, P=0.10$ ), and $6 \mathrm{~h}$ (mean $2.54 \pm 0.43 \%$ $\left.{ }^{14} \mathrm{C} / \mathrm{h}, P=0.10\right)$ after the ingestion of a glass of grapefruit juice.

The pharmacokinetics of a 10-mg oral dose of felodipine were determined when given with a glass of water (day 4), with the 1st (day 6), and the 16th glass of grapefruit juice (day 11). The mean felodipine blood levels observed after each of these doses are shown in Fig. 5. The peak concentration $\left(C_{\max }\right)$ and area under the curve over $12 \mathrm{~h}$ were determined from the blood concentration-time plots and are shown in Table II. The effect of the first glass of grapefruit juice was to increase the mean felodipine $C_{\max }$ from $5.5 \pm 3.4 \mathrm{nmol} /$ liter (with water) to $17.9 \pm 3.3 \mathrm{nmol} / \mathrm{liter}$; a $225 \%$ increase $(P=0.0001$, Table II). The mean felodipine AUC also increased $116 \%$, from $35.3 \pm 21.6 \mathrm{nmol} \cdot \mathrm{h} / \mathrm{liter}$ with water to $76.4 \pm 15.6 \mathrm{nmol} \cdot \mathrm{h} / \mathrm{liter}$ with the initial glass of grapefruit juice $(P=0.0001$, Table II).

Contrary to our hypothesis that the effect of grapefruit juice would diminish with continued ingestion, the mean $C_{\max }$ $(23.9 \pm 8.53 \mathrm{nmol} /$ liter $)$ and AUC $(109.8 \pm 35.3 \mathrm{nmol} \cdot \mathrm{h} / \mathrm{liter})$ observed when felodipine was taken with the 16 th glass of grapefruit juice were 34 and $44 \%$ greater than the respective mean values observed with the initial glass of grapefruit juice $(P=$ 0.044 and 0.0023 , respectively; see Table II).

Grapefruit juice also affected the coefficient of variation for $C_{\max }$ and AUC. The coefficient of variation of $C_{\max }$ was reduced from $61 \%$, when the felodipine was given with water, to $18 \%(P<0.05)$ when the drug was given with the first glass of grapefruit juice, and to $36 \%(P<0.05)$ when given with the 16th glass of grapefruit juice. Similarly, the coefficient of variation of AUC when given with water was significantly reduced from 61 to $20 \%(P<0.05)$ with the first glass of grapefruit juice and to $32 \%(P<0.05)$ after repeated grapefruit juice ingestion.

The magnitude of the increase in felodipine $C_{\max }$ and AUC produced by grapefruit juice varied considerably among the 10 subjects (range $64-597 \%$ and $4-368 \%$, respectively). Since we have previously demonstrated that there are substantial interindividual differences in the concentrations and activities of CYP3A4 in small bowel enterocytes (32), we examined whether this variability could account for the interindividual differences in the magnitude of drug interaction produced by grapefruit juice. There was a significant correlation between the enterocyte concentration of CYP3A4 measured before starting grapefruit juice treatment (day 5) and the increase in $C_{\max }$ observed (expressed as a ratio relative to the level when felodipine was given with water) after both acute (day 6) and repeated (day 11) grapefruit juice administration $(r=0.67$, $P=0.043$, and $r=0.71, P=0.022$, respectively). Subjects with the highest enterocyte concentration of CYP3A4 demonstrated the largest increases in $C_{\max }$ values. The percent decrease in enterocyte CYP3A4 concentration from day 5 to day 12 also correlated with the increase in $C_{\max }$ with either acute ( $r=-0.78, P=0.019)$ or repeated $(r=-0.64, P=0.048)$ grapefruit juice administration. The correlation between enterocyte CYP3A4 concentration before starting grapefruit juice (day 5) and the increase in AUC was not statistically significant with the initial dose of juice $(r=0.20, P=0.58)$, but was significant with recurrent grapefruit juice treatment $(r=$ $0.67 ; P=0.033)$. There were no significant correlations between the increase in either felodipine $C_{\max }$ or AUC with acute or prolonged grapefruit juice treatment (relative to water) and enterocyte concentrations of P-glycoprotein, CYP2D6, CYP1A1, or the ERMBT result (data not shown).

We also examined the relationships between the measured variables and the absolute values of dose-corrected (milligrams per kilogram) $C_{\max }$ and AUC at each time point. The enterocyte concentration of CYP3A4 measured before grapefruit juice (day 5) was significantly correlated with the $C_{\max }$ of felodipine when given with water $(r=-0.66, P=0.048$, data not shown). However, enterocyte CYP3A4 concentration after grapefruit juice administration (day 12) did not significantly correlate with the $C_{\max }$ of felodipine observed with either acute or repeated grapefruit juice ingestion. Neither the ERMBT result or the enterocyte P-glycoprotein concentration correlated with the $C_{\max }$ observed at any of the three time 
points. The ERMBT result before grapefruit juice ingestion (day 4) did not correlate with the AUC of felodipine when given with water $(r=-0.55, P=0.10)$. However, the ability of the ERMBT to predict AUC improved with grapefruit juice treatment. The day 4 ERMBT result was weakly correlated with the AUC of felodipine given with the first glass of grapefruit juice $(r=-0.62, P=0.053)$ and the correlation between the ERMBT result (day 11) and felodipine AUC was more significant after repeated grapefruit juice ingestion $(r=-0.68$, $P=0.029)$. Neither enterocyte CYP3A4 or P-glycoprotein concentration were significantly correlated with felodipine AUC at any time point.

\section{Discussion}

We initially hypothesized that recurrent grapefruit juice administration would result in an increase in the intestinal content of CYP3A4 and that, as a result, the magnitude of the effect of grapefruit juice on felodipine oral kinetics would diminish. Instead, we found that recurrent grapefruit juice administration resulted in an unequivocal decrease in enterocyte CYP3A4 protein concentration in the 10 subjects (Table I and Figs. 1 and 2). Furthermore, the effect of grapefruit juice on felodipine oral kinetics was significantly increased rather than reduced after recurrent grapefruit juice exposure compared with when the drug was taken with the first glass (see Table II and Fig. 5). The fall in enterocyte CYP3A4 protein concentration with grapefruit juice was accompanied by a similar drop in the enterocyte levels of CYP3A5 protein (see Table I and Fig. 3). However, this effect appeared to be specific for proteins within the CYP3A subfamily because there was no consistent change in the level of P-glycoprotein, or in the levels of two other intestinal cytochrome P450s, CYP2D6 and CYP1A1 (see Table I and Figs. 2 and 3).

The effect of grapefruit juice on CYP3A was limited to the small intestine as there was no detectable change in the level of CYP3A protein in biopsies of colonic mucosa (Fig. 4), which predominantly contains CYP3A5 (46). Although it is possible that the regulation of CYP3A5 protein in colon differs from that in small intestine, a more likely explanation is that the active component(s) of grapefruit juice are completely degraded or absorbed in the small bowel and never reach the distal colon where the biopsies were obtained. There was also no detectable effect of grapefruit juice on liver CYP3A4 activity as determined by the ERMBT. Although the second ERMBT was performed $\sim 14 \mathrm{~h}$ after grapefruit juice ingestion (day 11), it is unlikely that this delay between grapefruit juice treatment and the performance of the ERMBT caused us to miss an effect on liver CYP3A4. We detected no significant change in the ERMBT result among the five individuals that had the ERMBT performed 2 and $6 \mathrm{~h}$ after ingesting a glass of grapefruit juice and the effect of grapefruit juice on oral felodipine kinetics is known to still be evident $24 \mathrm{~h}$ after ingestion (47). Thus, the lack of change in the mean ERMBT result presumably indicates that the active ingredients do not reach the liver in sufficient concentrations to cause the effect.

The fall in enterocyte concentration of CYP3A4 protein during grapefruit juice treatment was not equivalent among individuals. As shown in Fig. 1, the magnitude of the drop appeared to depend largely on the initial CYP3A4 concentration; subjects with the highest starting levels of CYP3A4 tended to have the largest fall. As a result, all 10 subjects had similar en- terocyte concentrations of CYP3A4 after receiving grapefruit juice, which were comparable with those observed in some subjects before ingesting grapefruit juice. If this finding is confirmed in larger studies, it would indicate that the effect of grapefruit juice may be to reduce everyone to a relatively low level of CYP3A4 protein expression that is still within the "normal" range. The reduction in the variation of enterocyte concentration of CYP3A4 may have accounted for the significant fall in the coefficients of variation of $C_{\max }$ and AUC during grapefruit juice administration (Table II). An important question unanswered by this study is whether the CYP3A4 protein remaining after grapefruit juice treatment is catalytically active. The observation that enterocyte CYP3A4 concentrations measured after recurrent grapefruit juice treatment were not correlated with the $C_{\max }$ of felodipine observed at that time suggests that the residual intestinal CYP3A4 was not catalytically active. However, there was relatively little variation in the enterocyte content of CYP3A4 after recurrent grapefruit juice administration (Fig. 1 and Table I), making the detection of a true correlation unlikely with only 10 subjects.

The fall in enterocyte CYP3A4 protein concentration during grapefruit juice ingestion was not associated with a reduction in CYP3A4 mRNA (Fig. 2 and Table I). The mechanism of the decrease in CYP3A4 protein is, therefore, unlikely to involve decreased gene transcription or reduced stability of mRNA, and most likely reflects either accelerated protein degradation or reduced mRNA translation. In a preliminary study, we obtained small bowel biopsies from one individual before and $4 \mathrm{~h}$ after drinking a single glass of regular strength grapefruit juice. The enterocyte CYP3A4 protein concentration in this individual decreased $47 \% 4 \mathrm{~h}$ after the administration of grapefruit juice (from 94.1 to 50.0, not shown). If this finding is confirmed in a larger study, it would suggest that the effect of grapefruit juice may be quite rapid. Earlier studies in mice and rats have shown that suicide inhibition of cytochrome P450 enzymes results in a rapid fall in hepatic, adrenal, and testicular expression of the inhibited cytochrome(s) (4850). We therefore speculate that a component(s) of grapefruit juice damages CYP3A4 through suicide inhibition resulting in accelerated degradation of the enzyme.

To our knowledge, the downregulation of CYP3A4 and CYP3A5 protein we observed in human small bowel represents the first example of a dietary component causing a decrease in an intestinal xenobiotic metabolizing enzyme in humans. Other investigators have shown that dietary components are capable of increasing the small intestinal activities of drug metabolizing enzymes in humans (51). Our fruit- and vegetable-free ("washout") diet, while not causing a change in mean enterocyte CYP3A4 concentration, did result in an increase in CYP3A4 concentration in some subjects and a decrease in CYP3A4 concentration in others (Fig. 1). Although this may be the result of random variation alone, it is tempting to speculate that some dietary components are capable of producing a "grapefruit juice-like" effect, whereas other dietary components are inducers of CYP3A4. If a person's diet contained more of the former, their removal would result in a rise in enterocyte CYP3A4 levels. Alternatively, if a diet contained more of the latter components, their removal would result in a fall in enterocyte CYP3A4 levels. However, a careful review of each subject's detailed diet diary for the $3 \mathrm{~d}$ before admission failed to identify any specific food items clearly associated with either effect. 
Our data also suggest that the oral kinetics of felodipine when taken with water is largely determined by the enterocyte content of CYP3A4. The enterocyte concentration of CYP3A4 measured just before ingestion of grapefruit juice (day 5) was significantly correlated with felodipine $C_{\max }$ with water and correlated with the magnitude of the increase in felodipine $C_{\max }$ with grapefruit juice. Consequently, subjects with the highest enterocyte concentrations of CYP3A4 had the lowest felodipine $C_{\max }$ values with water and the greatest increase in felodipine $C_{\max }$ with grapefruit juice. Similar but weaker correlations were found between the intestinal CYP3A4 protein levels and felodipine AUC with water and with the fold increase in AUC with grapefruit juice ingestion. The weaker correlations with AUC are to be expected since AUC is more dependent than $C_{\max }$ on the rate of elimination of felodipine once it has entered the systemic circulation. Our data would suggest that future studies examining the clinical significance of drug interactions with grapefruit juice should focus on subjects with relatively high enterocyte CYP3A4 expression.

The important role of enterocyte CYP3A4 in oral felodipine kinetics is also supported by the observation that a correlation between liver CYP3A4 activity, as measured by the ERMBT, and the AUC of felodipine became significant only when subjects took the drug with grapefruit juice. Conversely, intestinal CYP3A4 measurements lost all predictiveness once the felodipine was taken with grapefruit juice. These observations are consistent with a shift of the bulk of felodipine metabolism from the intestine to the liver with grapefruit juice treatment. That is, once the intestinal component of felodipine metabolism is reduced by loss of intestinal CYP3A4, the oral kinetics of felodipine became more dependent on systemic clearance by hepatic CYP3A4.

Earlier attempts to identify the active ingredient(s) in grapefruit juice have involved screening components for their ability to inhibit CYP3A activity in liver microsomes (21-23). The identification of the reduction in intestinal CYP3A4 protein as a mechanism underlying the effect of grapefruit juice argues that intact cell systems will be required to identify the active ingredient(s). The addition of such natural and presumably safe substances to oral formulations of CYP3A4 substrates may reduce the costs and improve the reliability of current and future medications.

\section{Acknowledgments}

This study was supported by NIH grants GM38149-11 (P.B. Watkins), GM53095-01 (K.S. Lown), MO1 RR00042 (University of Michigan General Clinical Research Center), and by a grant from the Medical Research Council of Canada (MA-11584).

\section{References}

1. Bailey, D.G., J.D. Spence, C. Munoz, and J.M.O. Arnold. 1991. Interaction of citrus juices with felodipine and nifedipine. Lancet. 337:268-269.

2. Fuhr, U., S. Harder, P. Lopez-Rojas, H. Muller-Peltzer, R. Kern, and A.H. Staib. 1994. Increase of verapamil concentrations in steady state by coadministration of grapefruit juice. Naunyn-Schmiedeberg's Arch. Pharmacol. 349: R134.

3. Benton, R.E., P.K. Honig, K. Zamani, L.R. Cantilena, and R.L. Woosley. 1996. Grapefruit juice alters terfenadine pharmacokinetics, resulting in prolongation of repolarization on the electrocardiogram. Clin. Pharmacol. Ther. 59: 383-388.

4. Weber, A., R. Jager, A. Borner, G. Klinger, R. Vollanth, K. Matthey, and
A. Balogh. 1996. Can grapefruit juice influence ethinylestradiol bioavailability? Contraception. 53:41-47.

5. Kupferschmidt, H.H.T., H.R. Ha, W.H. Ziegler, P.J. Meier, and S. Krähenbühl. 1995. Interaction between grapefruit juice and midazolam in humans. Clin. Pharmacol. Ther. 58:20-28.

6. 1996. Saquinavir with grapefruit juice. Posit. Aware 7:5.

7. Ducharme, M.P., R. Provenzano, M. Dehoorne-Smith, and D.J. Edwards. 1993. Trough concentrations of cyclosporine in blood following administration with grapefruit juice. Br. J. Clin. Pharmacol. 36:457-459.

8. Ducharme, M.P., L.H. Warbasse, and D.J. Edwards. 1995. Disposition of intravenous and oral cyclosporine after administration with grapefruit juice. Clin. Pharmacol. Ther. 57:485-491.

9. Edgar, G., C.G. Regardh, G. Johnsson, L. Johansson, P. Lundborg, I. Lofberg, and O. Ronn. 1985. Felodipine kinetics in healthy men. Clin. Pharmacol. Ther. 38:205-211.

10. Wu, C.Y., L.Z. Benet, M.F. Hebert, S.K. Gupta, M. Rowland, D.Y. Gomez, and V.J. Wacher. 1995. Differentiation of absorption and first pass gut and hepatic metabolism in humans: studies with cyclosporine. Clin. Pharmacol. Ther. 58:492-497.

11. Fromm, M.F., D. Busse, H.K. Kroemer, and M. Eichelbaum. 1996. Differential induction of prehepatic and hepatic metabolism of verapamil by rifampin. Hepatology. 24:798-801.

12. Paine, M.F., D.D. Shen, K.L. Kunze, J.D. Perkins, C.L. Marsh, J.P. McVicar, D.M. Barr, B.S. Gillies, and K.E. Thummel. 1996. First-pass metabolism of midazolam by the human intestine. Clin. Pharmacol. Ther. 60:14-24.

13. Guengerich, F.P., W.R. Brian, M. Iwasaki, M.-A. Sari, C. Baarnhielm, and P. Berntsson. 1991. Oxidation of dihydropyridine calcium channel blockers and analogues by human liver cytochrome P450 IIIA4. J. Med. Chem. 34:18381844 .

14. Yun, C.H., R.A. Okerholm, and F.P. Guengerich. 1993. Oxidation of the antihistaminic drug terfenadine in human liver microsomes. Role of cytochrome P-450 3A(4) in N-dealkylation and C-hydroxylation. Drug Metab. Dispos. 21:403-409.

15. Guengerich, F.P. 1988. Oxidation of $17 \alpha$ ethinyl estradiol by human liver cytochromes P450. Mol. Pharmacol. 33:500-508.

16. Gorski, J.C., F.D. Hall, D.R. Jones, M. Vandenbranden, and S.A Wrighton. 1993. Midazolam metabolism to 4-OH midazolam and $1^{\prime} \mathrm{OH}-m i d-$ azolam by human cytochrome P450 3A. Clin. Pharmacol. Ther. 53:188.(Abstr.)

17. Aoyama, T., S. Yamano, D.J. Waxman, D.P. Lapenson, U.A. Meyer, V. Fischer, R. Tyndale, T. Inaba, W. Kalow, H.V. Gelboin, and F.J. Gonzalez. 1989. Cytochrome P-450 hPCN3, a novel cytochrome P-450IIIA gene product that is differentially expressed in adult human liver. cDNA and deduced amino acid sequence and distinct specificities of cDNA-expressed hPCN1 and hPCN3 for the metabolism of steroid hormones and cyclosporine. J. Biol. Chem. 264: 10388-10395.

18. Shimada, T., H. Yamazaki, M. Mimura, Y. Inui, and F.P. Guengerich. 1994. Interindividual Variations in human liver cytochrome P-450 enzymes involved in the oxidation of drugs, carcinogens and toxic chemicals: studies with liver microsomes of 30 Japanese and 30 Caucasians. J. Pharmacol. Exp. Ther. 270:414-423.

19. Watkins, P.B., S.A. Wrighton, E.G. Schuetz, D.T. Molowa, and P.S. Guzelian. 1987. Identification of glucocorticoid-inducible cytochromes P-450 in the intestinal mucosa of rats and man. J. Clin. Invest. 80:1029-1036.

20. Kolars, J.C., P. Schmiedlin-Ren, J.D. Schuetz, C. Fang, and P.B. Watkins. 1992. Identification of rifampin-inducible P450IIIA4 (CYP3A4) in human small bowel enterocytes. J. Clin. Invest. 90:1871-1878.

21. Guengerich, F.P., and D.H. Kim. 1990. In vitro inhibition of dihydropyridine oxidation and aflatoxin B1 activation in human liver microsomes by naringenin and other flavonoids. Carcinogenesis (Oxf.). 11:2275-2279.

22. Miniscalco, A., J. Lundahl, C.G. Regardh, B. Edgar, and U.G. Eriksson. 1992. Inhibition of dihydropyridine metabolism in rat and human liver microsomes by flavonoids found in grapefruit juice. J. Pharmacol. Exp. Ther. 261: 1195-1199.

23. Edwards, D.J., F.H. Bellevue, and P.M. Woster. 1996. Identification of $6^{\prime}, 7^{\prime}$-dihydroxybergamottin, a cytochrome $\mathrm{P} 450$ inhibitor, in grapefruit juice. Drug Metab. Dispos. 24:1287-1290.

24. Wang, S.X., T.A. Sutfin, C. Baarnhielm, and C.G. Regardh. 1989. Contribution of the intestine to the first-pass metabolism of felodipine in the rat. $J$. Pharmacol. Exp. Ther. 250:632-636.

25. Kolars, J.C., W.M. Awni, R.M. Merion, and P.B. Watkins. 1991. Firstpass metabolism of cyclosporin by the gut. Lancet. 338:1488-1490.

26. Bailey, D.G., J.M.O. Arnold, J.R. Bend, L.T. Tran, and J.D. Spence. 1995. Grapefruit juice-felodipine interaction: reproducibility and characterization with the extended release drug formulation. Br. J. Clin. Pharm. 40:135-140.

27. Hostetler, K.A., S.A. Wrighton, D.T. Molowa, P.E. Thomas, W. Levin, and P.S. Guzelian. 1989. Coinduction of multiple hepatic cytochrome P-450 proteins and their mRNAs in rats treated with imidazole antimycotic agents. Mol. Pharmacol. 35:279-285.

28. Schmiedlin-Ren, P., P.E. Benedict, W.O. Dobbins III, M. Ghosh, J.C. Kolars, and P.B. Watkins. 1993. Cultured adult rat jejunal explants as a model for studying regulation of CYP3A. Biochem. Pharmacol. 46:905-918.

29. Wrighton, S.A., P. Maurel, E.G. Schuetz, P.B. Watkins, B. Young, and 
P.S. Guzelian. 1985. Identification of the cytochrome P-450 induced by macrolide antibiotics in rat liver as the glucocorticoid responsive cytochrome P-450p. Biochem. 24:2171-2178.

30. Watkins, P.B., S.A. Wrighton, P. Maurel, E.G. Schuetz, G. MendezPicon, G.A. Parker, and P.S. Guzelian. 1985. Identification of an inducible form of cytochrome P-450 in human liver. Proc. Natl. Acad. Sci. USA. 82:6310-6314.

31. Bonkovsky, H.L., H.P. Hauri, U. Marti, R. Gasser, and U.A. Meyer. 1985. Cytochrome P450 of small intestinal epithelial cells. Immunochemical characterization of the increase in cytochrome P450 caused by phenobarbital. Gastroenterology. 88:458-467.

32. Lown, K.S., J.C. Kolars, K.E. Thummel, J.L. Barnett, K.L. Kunze, S.A. Wrighton, and P.B. Watkins. 1994. Interpatient heterogeneity in expression of CYP3A4 and CYP3A5 in small bowel. Lack of prediction by the erythromycin breath test [published erratum appears in Drug Metab. Dispos. 1995. 23(3): following table of contents]. Drug Metab. Dispos. 22:947-955.

33. Wrighton, S.A., W.R. Brian, M.A. Sari, M. Iwasaki, F.P. Guengerich, J.L. Raucy, D.T. Molowa, and M. Vandenbranden. 1990. Studies on the expression and metabolic capabilities of human liver cytochrome P450IIIA5 (HLp3). Mol. Pharmacol. 38:207-213.

34. Cribb, A., C. Nuss, and R. Wang. 1995. Antipeptide antibodies against overlapping sequences differentially inhibit human CYP2D6. Drug Metab. Dispos. 23:671-675.

35. Thiebaut, F., T. Tsuruo, H. Hamada, M.M. Gottesman, I. Pastan, and M.C. Willingham. 1987. Cellular localization of the multidrug-resistance gene product P-glycoprotein in normal human tissues. Proc. Natl. Acad. Sci. USA. $84: 7735-7738$.

36. Chomczynski, P., and N. Sacchi. 1987. Single-step method of RNA isolation by acid guanidinium thiocyanate-phenol-chloroform extraction. Anal. Biochem. 162:156-159.

37. Lown, K., J. Kolars, K. Turgeon, R. Merion, S.A. Wrighton, and P.B. Watkins. 1992. The erythromycin breath test selectively measures P450IIIA in patients with severe liver disease. Clin. Pharmacol. Ther. 51:229-238.

38. Watkins, P.B., S.A. Murray, L.G. Winkelman, D.M. Heuman, S.A. Wrighton, and P.S. Guzelian. 1989. Erythromycin breath test as an assay of glucocorticoid-inducible liver cytochromes P-450. Studies in rats and patients. $J$. Clin. Invest. 83:688-697.

39. Turgeon, D.K., A.B. Leichtman, K.S. Lown, D.P. Normolle, G.M. Deeb, R.M. Merion, and P.B. Watkins. 1994. P450 3A activity and cyclosporine dosing in kidney and heart transplant recipients. Clin. Pharmacol. Ther. 56:253-

40. Ahnoff, M. 1984. Determination of felodipine in plasma by capillary gas chromatography with electron capture detection. J. Pharmacol. Biomed. Anal. 2:519-526.

41. Chen, C., J.E. Chin, K. Ueda, D.P. Clark, I. Pastan, M.M. Gottesman, and I.B. Roninson. 1986. Internal duplication and homology with bacteria transport proteins in the $m d r 1$ (P-glycoprotein) gene from multidrug-resistan human cells. Cell. 47:381-389.

42. Hsing, S., Z. Gatmaitan, and I.M. Arias. 1992. The function of Gp170, the multidrug-resistance gene product, in the brush border of rat intestinal mucosa. Gastroenterology. 102:879-885.

43. Wacher, V.J., C.Y. Wu, and L.Z. Benet. 1995. Overlapping substrate specificities and tissue distribution of cytochrome P4503A and P-glycoprotein implications for drug delivery and activity in cancer chemotherapy. Mol. Carcinog. 13:129-134.

44. Saeki, T., K. Ueda, Y. Tanigawara, R. Hori, and T. Komano. 1993. Human P-glycoprotein transports cyclosporin A and FK506. J. Biol. Chem. 268: 6077-6080.

45. Smit, J.J.M., A.H. Schinkel, C.A.A.M. Mol, D. Majoor, W.J. Mooi, A.P.M. Jongsma, C.R. Lincke, and P. Borst. 1994. Tissue distribution of the human MDR3 P-glycoprotein. Lab. Invest. 71:638-649.

46. Kolars, J.C., K.S. Lown, P. Schmiedlin-Ren, M. Ghosh, C. Fang, S.A. Wrighton, R.M. Merion, and P.B. Watkins. 1994. CYP3A gene expression in human gut epithelium. Pharmacogenetics. 4:247-259.

47. Lundahl, J., C.G. Regardh, B. Edgar, and G. Johnsson. 1995. Relationship between time of intake of grapefruit juice and its effect on pharmacokinetics and pharmacodynamics of felodipine in healthy subjects. Eur. J. Clin. Pharmacol. 49:61-67.

48. Tierney, D.J., A.L. Haas, and D.R. Koop. 1992. Degradation of cytochrome P450 2E1: selective loss after labilization of the enzyme. Arch. Biochem. Biophys. 293:9-16.

49. Tephly, T.R., K.A. Black, M.D. Green, B.L. Coffman, G.A. Dannan, and F.P. Guengerich. 1986. Effect of the suicide substrate 3,5-diethoxycarbonyl-2,6-dimethyl-4-ethyl-1,4-dihydropyridine on the metabolism of xenobiotics and on cytochrome P-450 apoproteins. Mol. Pharmacol. 29:81-87.

50. Menard, R.H., T.M. Guenthner, H. Kon, and J.R. Gillette. 1979. Studies on the destruction of adrenal and testicular cytochrome P-450 by spironolactone. J. Biol. Chem. 254:1726-1733.

51. Hoensch, H., H. Steinhardt, G. Weiss, D. Haug, A. Maier, and H. Malchow. 1984. Effects of semisynthetic diets on xenobiotic metabolizing enzyme activity and morphology of small intestinal mucosa in humans. Gastroenterology. 86:1519-1530. 